\title{
Physical Fitness Training Program Using Electronic Simulation Games to Foster Psychological Health among University Students during COVID-19 Pandemic
}

\author{
Abeer Rasheed, Rania Abduljawad, Sherrin Mabrouk, Malek Jdaitawi*, Mona Abdulmonem \\ Self-development Department, Deanship of Preparatory Year \& Supporting Studies, Imam Abdulrahman bin Faisal University, Saudi \\ Arabia
}

Received January 23, 2021; Revised March 22, 2021; Accepted April 18, 2021

\section{Cite This Paper in the following Citation Styles}

(a): [1] Abeer Rasheed, Rania Abduljawad, Sherrin Mabrouk, Malek Jdaitawi, Mona Abdulmonem, "Physical Fitness Training Program Using Electronic Simulation Games to Foster Psychological Health among University Students during COVID-19 Pandemic," International Journal of Human Movement and Sports Sciences, Vol. 9, No. 3, pp. 421 - 427, 2021. DOI: $10.13189 /$ saj.2021.090305.

(b): Abeer Rasheed, Rania Abduljawad, Sherrin Mabrouk, Malek Jdaitawi, Mona Abdulmonem (2021). Physical Fitness Training Program Using Electronic Simulation Games to Foster Psychological Health among University Students during COVID-19 Pandemic. International Journal of Human Movement and Sports Sciences, 9(3), 421 - 427. DOI: 10.13189/saj.2021.090305.

Copyright $\mathrm{C} 2021$ by authors, all rights reserved. Authors agree that this article remains permanently open access under the terms of the Creative Commons Attribution License 4.0 International License

\begin{abstract}
Recently, technology has been suggested as an effective tool during COVID-19 pandemic. Therefore, this study examines the physical training fitness activities using electronic simulation games on fostering psychological health among university students during COVID-19 pandemic. A quasi-experimental pre-post-test design was employed. Students were divided into two groups, one experimental and the other controlled. The research community included female students at the preparatory year and supporting studies deanship at Imam Abdulrahman bin Faisal University in Saudi Arabia. The data were collected from a sample of 24 female students during the first semester of the academic year (2020-2021). The results revealed that the experimental group attained higher mean scores than students in control group in the study variables. The result of this study evidenced that game simulation devices promote positive psychological health among students. The study concluded that technology devices can be used for exercises and can be very effective in the teaching and learning process of physical education courses.
\end{abstract}

Keywords COVID-19, Fitness Activities, Technology, Electronic Simulation Games

\section{Introduction}

In recent times, the impact of Covid-19 on the life aspects of all people in every part of the world $[1,2,3,4]$ has become evident. Among the many issues related to the above activities include excessive body weight gain, low physical activity, psychological and mental problems, which have all been manifested during the pandemic $[4,5]$. Because of the Covid-19 pandemic, millions of people have been forced to stay at home, which is a confined space, with some self-isolating - these actions adversely impact their behaviors, physical health, wellbeing, patterns of sleeping and life quality [6]. For this reason, individuals applied psychological interventions to minimize the negative psychological effect on individual life during COVID-19 pandemic. Computers and their applications are significant features of the modern era and they have dominated all aspects of human activities. Applications of the computer technology which can be used in training include electronic games which are characterized by suspense, excitement and entertainment. In other words, electronic games help in acquiring and developing the ability to solve problems and apply knowledge in situations similar to reality $[7,8,9]$.

In addition, they provide immediate feedback, train users to depend on themselves, and develop their critical thinking 
by following organized steps in analyzing and evaluating information to reach the correct result. Electronic simulation is a method or technique usually used to bring the trainee closer to the real world that is difficult to provide and is one of the most important training methods relied upon to rationalize financial costs, time and human effort. Recently, several technologies applications developed for various purposes (education, entertainment, training and mental health) such as "the Xbox 360". Among its features, the device contains the Live feature, which allows online playing. It is considered the best network for players in the world due to its affordable price compared with other games. It also contains a graphics card that is considered the best in all gaming devices and has the ability to play $3 \mathrm{D}$ surround sound with high or low frequency movement and activity during the game. The device reflects the movements of the player's body through the sensor and the area designated for playing. Sound, image and graphics are of high quality. As players can view their performance after completion as the Kinect sensor works to record a video of all the player's movements, the players' experience during a virtual environment is somehow similar to reality.

However, literature supported the advantages of playing electronic games, including fencing games in developing the ability to innovate and make decisions, overcome problems, and learn the law of fencing through the general information and educational programs they contain, which plays a positive role in developing learners' abilities and helping them to integrate into the world of information technology and machines [10]. The university seeks to achieve comprehensive and integrated development for learners including cognitive, emotional, physical and social aspects. This situation prompted the researchers to think of a training method to develop physical fitness and raise the level of mental health for students. Hence, electronic simulation using three-dimensional technology (Xbox 360) was suggested to impact the psychological health of the students. When it comes to using digital technology applications and its impact on individual physical and psychological health, literature still requires more studies $[11,12]$. From the few available studies in literature, Ref [13] recommended the apps capability of providing content delivery effectiveness and efficiency as strategies to promote iGeneration. Also, Ref [14] provided participants with iPads to move different fitness stations and record heart rates, and they found the app to be effective in motivating the students and bringing about their learning of physiological knowledge. Other related studies like De Meester et al. [15] cited the use of music, timer and whiteboard apps for classroom management (environmental), for promoting physical activity behaviors (behavioral) and students' enjoyment (personal). Also, individuals that used video-based tool displayed more autonomy, competence and relatedness satisfaction as well as autonomous motivation [16]. Hence, the study aimed at examining the physical fitness training program using electronic simulation games to foster psychological health among university students during COVID-19 pandemic.

\section{Materials and Methods}

The study was conducted in Dammam city, east region in Saudi Arabia during the first few weeks in the first term in September 2020. The researchers touched on the importance of the community they work in, which is the university community and the extent of the impact that their work can have to improve the health of female students and get them used to practicing sports and to increase that importance of technology devices in their daily activities. The study was conducted at Imam Abdulrahman bin Faisal University in east region of Saudi Arabia. The university was chosen as it is on the first university in the Kingdom where this course is taught with a practical part, and to foster psychological health among students.

\subsection{Design}

Quasi-experimental pre-posttest design was implemented in this study. In this study, a quantitative quasi-experimental approach was adopted using a pre- and post-test, coupled with control group design. A survey was designed and used to determine the users' expectations, abilities, views and thoughts as suggested by $[17,18,43,44]$. The survey design was also adopted by studies of this nature [16].

\subsection{Sample and Procedures of the Study}

The sample of the study comprised of twenty-four (24) students in Dammam, Eastern Saudi Arabia. The sample members were selected using purposive sampling approach and were requested for their participation. They were also selected based on their willingness to participate and their ownership of x-box 360 device, as well as their commitment towards the period of study. While a total of 24 students completed the study procedures, an additional 8 students participated in the pilot study measures. The 24 students were divided into two: 12 in the experimental group and 12 in the control group. Initially, the author provided a thorough overview of the experiment format and answered students' queries. The pilot study was conducted in a span of 10 days after which the students went to two preparation sessions that spanned for a period from $21^{\text {st }}$ September to $1^{\text {st }}$ October 2020. The students were exposed to manipulated videos of activities related to the study aims, the workings of $x$-box 360 , and their consent to begin the experiment was sought. Following the video watching, the students had to fill out questionnaires to confirm credibility and to assess their physical fitness level and psychological health prior to the experiment.

\subsection{Experimental X BOX 360 Design}

The design quality was adapted and extended to meet the abilities and skills of the students. In the first stage, the features and appropriate elements needed were identified, where the design features refer to the collection of features 
incorporated. The features display the whole scenario, particularly on the execution of process and games functionality. Some of the games related to the study experimental activities are demonstrated in the following figures. The study primarily used six loco-motor skills namely running, hopping, galloping, leaping, horizontal jumping and sliding, along with six object control skills, namely striking, dribbling, catching, kicking, overhand throwing and underhand rolling.

\subsection{Instruments}

The measurement used for Psychological health gauged the Psychological health impacts of the students, where the items were adapted to certain physical fitness context following studies in literature $[19,20]$. The scale was developed in several stages. First, the items were developed and modified from the relevant literature in psychological health. After generating the initial items pool, this study employed the Q-sort technique and experts review to examine the face validity of the items. A q-sort technique was utilized to determine the relevance of the items to their respective factors. Ten experts in the field of sport and psychology conducted the Q-sort test, retaining items with over $80 \%$ consensus percentages [40]. A total of 68 items were prepared for the pilot study with 8 students to improve the reliability and validity of the scale due to their willingness in participating in this study. Based on the results, the scale comprised of 6 sub-scales, with a total of 68 items. Each sub-scale measured by several items that were scaled on a 5-point Likert scale ranging from 1 (strongly disagree) to 5 (strongly agree).

Specifically, the 6 sub-scales covered emotional balance, self-determinants, personal and social adjustment, social relations, entertainment and personal skills. Moreover, the scale was tweaked by modifying the statement into "During the exercise lesson that I practiced...", after which the items reflecting emotional balance consisted of (11 items with $\alpha$ $=0.94$ ) such items (I can control my negative effeling), followed by self-determinants ( 10 items with $\alpha=0.96$ ) such item (I find difficulties to make my own decisions), then personal and social adjustment (12 items with $\alpha=0.96$ ) such as (I feel that people cannot understand me), social relations (14 items with $\alpha=0.93$ ) such as (I feel people do not have much confidence in me), entertainment (10 items with $\alpha$ $=0.94$ ) such as (I know how to enjoy doing my tasks), and personal skills ( 11 items with $\alpha=0.90$ ) such as (I am able to overcome any obstacles on my way to achieve my goal). The value of the total Cronbach's alpha value of psychological health measure is $\alpha=0.71$.
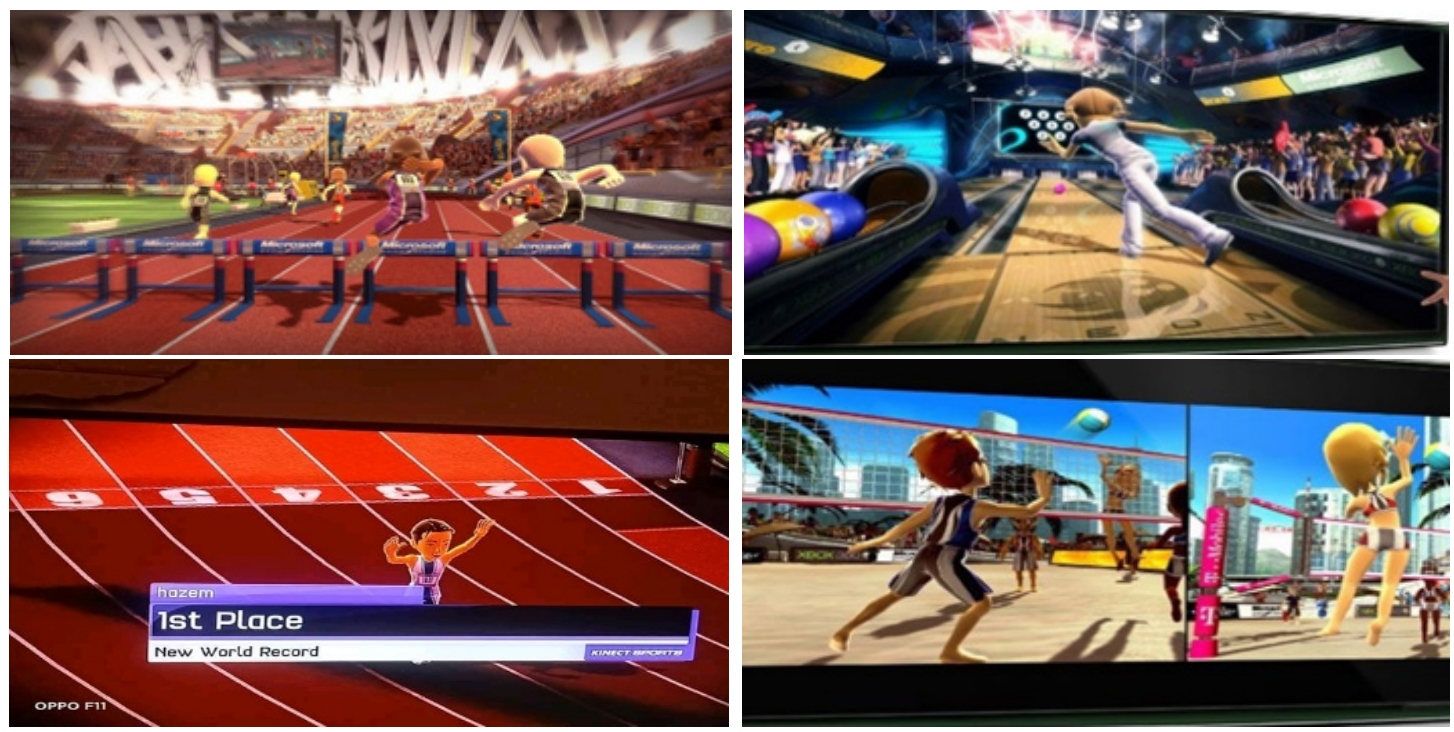

Figures 1. Experimental Activities 


\section{Results}

On examining the results obtained from the two groups, the mean and standard deviation vales in the pre and post-test scores of dependent variables are presented in Table 1. Specifically, for the psychological health measure, the table 2 shows that experimental group had mean pretest $(\mathrm{M}=133.43, \mathrm{SD}=2.45)$, and post-test values of $(\mathrm{M}=155.62$, $\mathrm{SD}=2.37$ ). Added to the above, based on the results in table 3 , the control group pre-test of psychological health scored less $(\mathrm{M}=132.75, \mathrm{SD}=2.97)$ compared to the post-test scores $(M=136.42, S D=2.26)$. Paired-sample t-test was used to determine significant differences between measure time of experimental group pre and post-test score of psychological health, and result was shown to be significant $(\mathrm{t}=16.63$, sig. $<0.05)$. Furthermore, based on the results, the psychological health pretest in control group also showed significant result with the values of $(\mathrm{t}=$ 2.70, sig. <0.05).

Comparing between the post-test scores of the two groups (control and experimental), based on the mean and standard deviation values displayed in table 4, this study found that experimental group had higher mean and SD values $(M=155.62, S D=2.37)$ in the psychological health measure compared to the control group $(\mathrm{M}=136.42, \mathrm{SD}=$ 2.26). Using paired sample t-test, significant differences were found between the post-test score of both groups in psychological health $(\mathrm{t}=28.12,<0.05)$.

Table 1. Results of the Descriptive Statistics of the study groups

\begin{tabular}{|c|c|c|c|c|}
\hline Variable & \multicolumn{2}{|c|}{ Experimental Group } & \multicolumn{2}{c|}{ Control Group } \\
\hline $\begin{array}{c}\text { Psychological Health } \\
\text { Pretest }\end{array}$ & 133.43 & 2.45 & 132.75 & 2.97 \\
\hline $\begin{array}{c}\text { Psychological Health } \\
\text { Posttest }\end{array}$ & 155.62 & 2.37 & 136.42 & 2.26 \\
\hline
\end{tabular}

Table 2. Results of the Paired sample t-test for the experimental group at $\mathrm{p}$ value $<0.05$

\begin{tabular}{|c|c|c|c|c|c|}
\hline & \multicolumn{2}{|c|}{ Pretest } & \multicolumn{2}{c|}{ Posttest } & t-value \\
\cline { 1 - 5 } Variable & \multirow{2}{*}{133.43} & 2.45 & 155.62 & 2.37 & $16.63^{*}$ \\
\cline { 1 - 5 } $\begin{array}{c}\text { Psychological } \\
\text { Health }\end{array}$ & & & & \\
\hline
\end{tabular}

Table 3. Results of the Paired sample t-test for the control group at $\mathrm{p}$ value $<0.05$

\begin{tabular}{|c|c|c|c|c|c|}
\hline & \multicolumn{2}{|c|}{ Pretest } & \multicolumn{2}{c|}{ Posttest } & t-value \\
\cline { 1 - 2 } Variable & 132.75 & 2.97 & 136.42 & 2.26 & $2.7^{*}$ \\
\cline { 1 - 5 } $\begin{array}{c}\text { Psychological } \\
\text { Health }\end{array}$ & 13.46 & & \\
\hline
\end{tabular}

Table 4. Results of the Paired sample posttest at $\mathrm{p}$ value $<0.05$

\begin{tabular}{|c|c|c|c|c|c|}
\hline & \multicolumn{2}{|c|}{ Experimental } & \multicolumn{2}{c|}{ Control } & t-value \\
\cline { 1 - 2 } Variable & 136.42 & 2.26 & 155.62 & 2.37 & $28.12 *$ \\
\cline { 1 - 5 } $\begin{array}{c}\text { Psychological } \\
\text { Health }\end{array}$ & 132 & & \\
\hline
\end{tabular}

\section{Discussion}

The purpose of this study was to examine the effect of the games on the students' psychological experiences after the experiment. The results show that there are statistically significant differences between the pre-measurement and the post-measurement of the experimental group in the psychological health scale and the questionnaire of impressions towards the training method under study in favor of the post measurement. The researchers attribute these differences to the electronic simulation program using the (xbox360) device, where fitness activities are important components closely related to health. Individuals must possess them in order to enjoy good health and have the ability to perform motor duties perfectly. The result may also be attributed to the fact that simulation games have positive cognitive and health effects on individuals as mentioned by the previous study [21]. Online games motivate students to exert higher effort levels towards activity performance and it encourages them to get involved in physical activities. The result is consistent with that of [22], who found a significant relationship between playing computer games and students' health. Other researchers also support that online games enhance several cognitive and health aspects of individuals, including reaction time, memory, attention, weight reduction and overall well-being [21,22]. However, the results were consistent with the studies of $[23,24]$, who supported the positive impact of the sport training programs and electronic games on increasing perception and motivation, flexibility, information processing and regularity in practicing movement ([41,42]. Games can have a significant role in the prevention of excessive weight gain. The use of electronic simulation as a method of competitive training helped the students in raising the level of physical fitness and commitment to training. The use of the (xbox360) device represents a new edifice in training because of its powerful technological applications working as a simulation method providing a virtual environment difficult or impossible to implement in reality, which encourage the researchers to carefully select the suitable games. The instructions given by the (Xbox) device in terms of sound, image and interaction during the application contributed positively to addressing more than one aspect. They also helped students to distribute their effort during the performance depending on the signal appearing on the screen. Signals are also given of any signs fatigue during the performance and the order of the player among her colleagues as well as hypotheticals competitors, which led to an improvement in the distribution of effort during the performance as pointed in the literature [25,26].

Literature proposes the use of several traditional motor skills training programs, such as video games as an alternative method for the instruction of physical and motor skills. Online video games can be used as an alternative form of exercise when basic motor learning elements are 
incorporated into them [27]. This type of games can provide real-time tasks practices and activities, and pave the way for intensive, meaningful, enjoyable and purposeful engagement in tasks that are related to actual real-life interests $[27,28]$. Prior studies in literature also evidenced that playing active video games for the purpose of education and physical activities can positively impact attitudes, intellectual skills, knowledge, motor skills and physical health related with both physical activity and physical education [29,30]. More specifically, Ref [30] reached to the conclusion that active video games can motivate people to engage in physical activities, while [29] shed light on the use of active video games impact on the cognitive and emotional levels of the players. This is consistent with the notions of 48,49 that the benefit of using the competitive method in increasing the motivation of the learner in the educational situation, which in turn improves performance level. On the whole, it can be stated that active video games training programs do enhance the motor skills, health and physical fitness of the students $[31,32]$.

The results also showed that there are statistically significant differences between the two-dimensional measures of the experimental and control groups in the psychological health scale and the questionnaire of impressions towards the training method under study and in favor of the experimental group. The researchers attribute the reason for the experimental group's advancement over the control group to the fact that the use of electronic simulation as a method for competitive training using the Xbox360 device is considered to be a revolution in the field of modern technology. Electronic simulation has enabled students' living in a virtual environment to exercise as if they are in a real environment. It has made it is easy for students and the trainers to do activities that are difficult to do otherwise, whether due to time, place, or the nature of these activities. Guiding students to perform the model on the screen helps students respond to instructions quickly resulting in a positive impact on their ability to access the best level during exercise. In addition, during performance, the device reflects the student's body movements through the Kinect sensor. The area designated for playing, sound, image and graphics are of high quality. A graphics card is considered the best in all gaming devices, and the ability to play the three-dimensional surround sound with high or low frequency motivated female students. In addition, the Xbox 360 has features that contributed to the development of performance by competing with the device or through female students competing with each other, competing at three levels (easy - medium - hard) and playing remotely with female colleagues, which raises female students' motivation to compete and achieve the best performances. Literature explored the beneficial contributions of game-based learning to cognitive, psychological and behavioral outcomes and based on the findings, online games can be used as a tool to effectively promote the acquisition of knowledge [33,34], and to comprehend the content and bring about conceptual learning $[35,36]$. Online games were also evidenced to be effective in the affective and behavioral domains in addition to the cognitive one $[37,38,36,39]$. This may be exemplified by the online games impact on the motivation, engagement and satisfaction of the students of game-based learning. As for behavioral outcomes, games pave the way for collaborative learning, improved interactivity and players' feedback, and development of social and soft skills.

\section{Conclusions}

In the light of the objectives, this study examined the effectiveness of video games simulation in the context of university and the findings indicated that majority of the prior studies in literature evidenced the positive outcomes and supported the effectiveness of online video games in satisfying the needs of university students, specifically when it comes to their psychological health. Prior studies also evidenced that students can maintain their weight and take active part in social and daily activities through video games. To conclude, the study showed that online video games are useful in assisting students to obtain various skills to satisfy their needs and to promote their societal engagement, for a normal social life. The students displayed positive psychological outcomes with enhanced physical fitness.

\subsection{Limitations and Recommendations}

This study has several limitations, with the first being data being gathered using self-report measures, thus, future studies may adopt a mixed approach to confirm the current study's which was suggested in previous studies [45]. Although, the study was implemented by the researchers, but it should be noted that the study conducted during COVID-19 pandemic quarantine, and students were contacted via online platform and according to their self-control. Thus, future studies should validate the study results by contacting in class sessions. The study sample consisted of students from a single Saudi university and thus, generalizability to all universities may not be feasible. Future studies, in this case, may extend the sample to other Saudi universities for a more generalizable outcome. Moreover, the study focused on specific skills and as such, future studies can explore skills other than the ones addressed in this study. Lastly, the sample comprised of female participants only and thus, future studies can include both genders and consider their individual abilities. 


\section{REFERENCES}

[1] B. Garcia-Garcia, M. James, D. Koller, J. Lindholm, D. Mavromati, R. Parrish, R. Rodenberg. The impact of Covid-19 on sports: a mid-way assessment, The International Sports Law Journal, Vol.20, 115-119, 2020. https://doi.org/10.1007/s40318-020-00174-8.

[2] D. Parnell, P. Widdop, A. Bond, R. Wilson. COVID-19, network and sport, Managing Sport and Leisure. 2020. Doi: 10.1080/23750472.2020.1750100.

[3] V. Ratten. Coronavirus disease (COVID-19) and sport entrepreneurship, International Journal of Entrepreneurial Behavior \& Research, 1356-2554. DOI10.1108/IJEBR-06-2 020-0387.2020.

[4] C. Zhang et al. The psychological impact of the COVID-19 pandemic on teenagers in China, Journal of Adolescent Health, Vol.67, 747-755, 2020.

[5] M. Simons, et al. Active video games as a tool to prevent excessive weight gain in adolescents: Rationale, design and methods of a randomized controlled trail, BMC Public Health, Vol.14, No275, 1-13, 2020.

[6] A. Hammami, B. Harrabi, M. Mohr, P. Krustrup. Physical activity and coronavirus disease 2019 (COVID-19): Specific recommendations for home-based physical training". Managing Sport and Leisure, 2020. http://doi.org/10.1080/2 3750472.2020 .1757494 .

[7] A. Marwa. The effectiveness of competition approach on the basic skills performance in volleyball among primary year students. Unpublished Master Thesis, Aleskandria University, Egypt. 2010.

[8] M. Hala. Training strategies and approaches in transform stage. Arab Center for publishing. 2004.

[9] A. Esam. Sort training: theories and applications. Knowledge Company. Egypt. 2003.

[10]A. Rasha. The strategies of training approach using electronic methods in maintaining fitness status among volleyball trainers. Unpublished Master Thesis, Aleskandria University, Egypt. 2011.

[11] T. Althogg, P. Jindal, J. Leskovec. Online actions with offline impact: How online social networks influence online and offline user behavior". Tenth ACM International Conference, February, 2017. Doi: 10.1145/3018661.301867 2. 2017.

[12] J. Krause, H. Franks, B. Lynch. Current technology trends and issues among health and physical education professionals, The Physical Educator, Vol.74, No.1, 164-180. 2017. Doi: 10.18666/TPE-2017-V74-I1-6648.

[13]X. Zhu, L. Dragon. Physical activity and situational interest in mobile technology integrated physical education: A preliminary study". Acta Gymnica, Vol.46, No.2, 2016. Doi: 10.5507/ag.2016.010.

[14]K. Sieberer-Nagler. Effective Classroom-Management \& Positive Teaching." English Language Teaching, Vol.9,No. 1, 163-172, 2016.

[15]F. De Meester, N. Aelterman, G. Muynck, L. Haerens . An experimental, video-based investigation into the motivating impact of choice and positive feedback among students with different motor competence levels, Physical Education and Sport Pedagogy, Vol.25, No.4, 361-378, 2020. DOI: 10.1080/17408989.2020.1725456.

[16] Fernandez-Rio, E. Heras, T. González, V. Trillo, J. Palomares. Gamification and physical education. Viability and preliminary views from students and teachers, Physical Education and Sport Pedagogy, Vol.25, No.5, 509-524, 2020. DOI: $10.1080 / 17408989.2020 .1743253$.

[17] J. Creswell. Five Qualitative Approaches to Inquiry, SAGE Publications, Inc. 2006.

[18] J. Fraenkel, N. Wallen. How to design and evaluate research in education (6th ed.). New York, NY: McGraw-Hill. 2006.

[19] A. Hannan. Psychological health and its recovery". World Book Publisher, Egypt. 2000.

[20] A. Sherrin, M. Halawah. Psychological Health application and Theory". Modern University Library. 2002.

[21] M. Mohammadi, A. Dehaghani, T. Mehrabi, D. Ali. Association between playing computer games and mental and social health among male adolescents in Iran in 2014. Iranian Journal of Nursing and Midwifery Research, Vol.21, No.2, 153-158, 2016.

[22]P. Toril, J. Reales, S. Ballesteros. Video game training enhances cognition of older adults; A meta-analytic study, Psychology Aging, Vol.29, No.3, 706-716, 2014.

[23] M. Dankbaar, J. Alsma, V. Jansen, J. Merrienboer, J. Saase, S. Schuit. An experimental study on the effects of a simulation game on students' clinical cognitive skills and motivation". Advances in health sciences education : theory and practice, Vol.21, No.3, 505-521, 2016. https://doi.org/10.1007/s1045 9-015-9641-x

[24] M. Zaki. New approach in sport training. Egypt Library, Egypt. 2004.

[25]A. Muhammad. Training foundations". Book Center Publisher, Egypt. 2006.

[26] A. Kamal. The foundation of human movements in human life and sport. Book Center Publisher, Egypt. 2009.

[27] C. Yen, K. Lin, K. Hu, M. Wu, R. Lu, T. Lin, C. Effects of virtual reality-augmented balance training on sensory organization and attentional demand for postural control in people with Parkinson disease: a randomized controlled trial, Physical Therapy, VOL.91, No.6, 862-874, 2011. doi:10.2522/ptj.20100050.

[28] N. Vernadakis, M. Papastergiou, E. Zetou, P. Antoniou. The impact of an exergame-based intervention on children's fundamental motor skills, Computers \& Education, Vol.83, 90-102, 2015. doi:10.1016/j.compedu.2015.01.001.

[29] A. Abdul, P. Felicia. Gameplay Engagement and Learning in GameBased Learning: A Systematic Review. Review of Educational Research. In Press. 2015. doi:10.3102/0034654 315577210 .

[30] V. Nurkkala, J. Kalermo, T. Jarvilehto, T. Development of Exergaming Simulator for Gym Training, Exercise Testing and Rehabilitation, Journal of Communication and Computer, 11, 403-411, 2014.

[31]C. Campos, H. Fernandez. The benefits of active video 
games for educational and physical activity approaches: A systematic review. New Approaches in Educational Research, Vol.5, No.2, 115-122, 2016.

[32] A. Gioftsidou, et al. Typical balance exercises or exergames for balance improvement? Journal of Back and Musculoskeletal Rehabilitation, 26(3), 299- 305, 2013.

[33].D. Clark, E. Tanner-Smith, S. Killingsworth. Digital games, design, and learning a systematic review and meta-analysis. Review of educational research, 86(1), 79-122, 2015. 0034654315582065 .

[34] J. Warren, M. Luctkar-Flude, C. Godfrey, J. Lukewich. A systematic review of the effectiveness of simulation-based education on satisfaction and learning outcomes in nurse practitioner programs, Nurse Education Today, Vol.46, 99$108,2016$.

[35] M.. Li, C. Tsai. Game-based learning in science education: A review of relevant research. Journal of Science Education and Technology, Vol.22, No.6, 877-898, 2013.

[36] K. Fu, T. Hainey, G. Baxter. A systematic literature review to identify empirical evidence on the use of computer games in business education and training. In 10th European Conference on Games Based Learning: ECGBL, (p. 232), 2016.

[37] A. Ritzhaupt, N. Poling, C. Frey, M. Johnson. A synthesis on digital games in education: What the research literature says from 2000 to 2010, Journal of Interactive Learning Research, Vol.25, No.2, 261-280, 2014.

[38] S. Shin, J. Park, J. Kim. Effectiveness of patient simulation in nursing education: Meta-analysis, Nurse Education Today,
Vol.35, No.1, 176-182, 2015.

[39] J. Carenys, S. Moya. Digital game-based learning in accounting and business education, Accounting Education, Vol.25, No.6, 598-651, 2016.

[40] Brown, S. (1980). Political subjectivity. Applications of Q methodology in political science. New Haven, CT: Yale University Press.

[41] S. Lotfi, I. Elmoutaraji, M. Talbi "Effect of Physical Exercise and Gender on Information Processing and Choice Reaction Time of University Students," International Journal of Human Movement and Sports Sciences, Vol. 8, No. 1, pp. 37 - 42, 2020. DOI: 10.13189/saj.2020.080105.

[42] K. Alper E. Ergin, "Investigation of the Effect of 6-week Yoga Exercises on Balance, Flexibility, and Strength in Soccer Players," International Journal of Human Movement and Sports Sciences, Vol. 8, No. 3, pp. 91 - 96, 2020. DOI: 10.13189/saj.2020.080303.

[43] M. Jdaitawi. Does flipped learning promote positive emotions in science education? A comparison between traditional and flipped classroom approaches. Electronic Journal of e-learning, 18(6), 516-524.

[44] M. Jdaitawi. The effect of using problem-based learning upon students emotions towards learning and levels of communication skills in three different disciplines. Croatian Journal of Education, 22(1), 207-240.

[45] L. Rababah, N. Bani-Melhem, M. Jdaitawi, B. Rababah, O. (2012). EFL teachers barriers to the use of ICT in instruction in Jordan. Paper presented at the $1^{\text {st }}$ International Conference on Behavioural and Social Science. 